\title{
A APLICAÇÃO DA ARQUIVÍSTICA INTEGRADA, CONSIDERANDO OS DESDOBRAMENTOS DO PROCESSO A PARTIR DA CLASSIFICAÇÃO
}

\author{
Olga Maria Correa Garcia \\ Vitor Francisco Schuch Junior
}

\begin{abstract}
Resumo
Investiga a aplicação da arquivística integrada, considerando os desdobramentos do processo a partir da classificação, nos trabalhos de final de curso dos graduandos em Arquivologia pela Universidade Federal de Santa Maria, no período de 1997 a 1999. Utiliza a técnica de análise de conteúdo, desenvolvida através de uma pré-análise das fontes, da exploração do material e do tratamento e interpretação dos resultados. Assim, conclui que, apesar de encontrar indícios de aplicação da arquivística tradicional, os graduandos, cada vez mais, reconhecem e aceitam a arquivística integrada, aplicando-a considerando os desdobramentos do processo a partir da classificação. Face às dificuldades e limitações apresentadas pelos graduandos, reconhece-se que são necessárias mudanças, no sentido de desenvolver e consolidar os programas de formação.

\section{Palavras-chave}

Arquivística; Arquivística integrada; Classificação documentária; Política de Gestão de Arquivos
\end{abstract}




\section{INTRODUÇÃO}

\subsection{0 tema e o problema}

A arquivística, como campo do conhecimento estabelecido no Século XX, apesar de algumas raízes mais antigas, encontra-se em ascensão. Muitas pesquisas e discussões vêm sendo realizadas com o objetivo de aprofundar conceitos e teorias nesta área.

A disciplina arquivística e os profissionais da área, considerando o acréscimo da produção de informação e o maior uso desta, têm o papel cada vez mais reconhecido na sociedade que servem, na medida em que contribuem com soluções para os problemas de gestão das informações, garantindo o acesso aos diferentes usuários.

$\mathrm{O}$ acesso à informação para as administrações é fundamental, pois a informação é um instrumento de apoio à decisão indispensável para que possam gerir suas organizações com vistas ao crescimento. A informação também pode servir de apoio à pesquisa científica; pode ainda ter por objetivo comprovar direitos; dar suporte ao ensino e à aprendizagem ou simplesmente informar.

No entanto, para que possam ser acessadas, constituindo fonte de conhecimento, é preciso que as informações estejam integradas num conjunto sistemático, estruturado e organizado.

Por isso, autores da atualidade defendem a arquivística integrada, procedimentos integrados que levam a uma visão global das informações no âmbito de uma organização, possibilitando um rápido acesso à informação. Para Lopes (1998), a arquivística integrada é a única a propor a transformação da arquivística numa disciplina científica, que se preocupa com o tra- tamento global das informações, da sua criação até o destino final.

Essa renovação conduz a "tratar das aplicações arquivísticas práticas, das soluções e problemas relacionados à classificação, à avaliação e à descrição" (Lopes, 1997, p.91). Defende-se, nesta última corrente de pensamento, que os procedimentos são complementares e inseparáveis, onde a classificação deve ser pensada a partir da criação dos documentos até o momento de sua destinação final.

A classificação, então, constitui a base dos demais procedimentos, considerando que a partir dela é possível realizar uma avaliação que leve a manter informações essenciais e necessárias e dispensar as supérfluas. A descrição, enquanto programa, tem início na classificação, estende-se no processo avaliativo até o destino final.

Muitos problemas são encontrados na literatura relativa à classificação, avaliação e descrição. Isto conduz a inúmeros questionamentos quando do fazer arquivístico, quando do ensino e quando da pesquisa.

Na prática profissional percebe-se que, na maioria das vezes, predominam práticas arquivísticas desempenhadas de forma simples e desintegradas, usadas sob o jargão da arquivística tradicional e do records management.

No campo da arquivística, em processo de desenvolvimento, está presente a insatisfação com os limites teóricos, considerando a carência de pesquisas científicas.

Assim, com a finalidade de contribuir para o aprimoramento do tema, a questão que norteia o presente trabalho é investigar qual a aplicação da arquivística inte- 
grada, considerando os desdobramentos do processo a partir da classificação, nos trabalhos de final de curso dos graduandos em Arquivologia pela Universidade Federal de Santa Maria (UFSM), no período 1997 a 1999?

\subsection{Objetivos}

O objetivo geral do presente estudo consiste em investigar a aplicação da arquivística integrada, considerando os desdobramentos do processo a partir da classificação, nos trabalhos de final de curso dos graduandos em Arquivologia pela UFSM, no período 1997 a 1999.

Em termos específicos pretende-se alcançar os seguintes objetivos:

- analisar a aplicação da arquivística integrada;

- identificar e analisar a interligação estabelecida entre os procedimentos, classificação, avaliação e descrição;

- analisar a aplicação do procedimento de classificação, considerando os métodos de classificação, a elaboração de planos de classificação e os resultados obtidos com a aplicação dos mesmos;

- analisar as relações estabelecidas entre as questões teórico-conceituais e a prática realizada;

- integrar teoria e prática através de investigações, de discussões e de reflexões sobre do tratamento da informação arquivística.

\subsection{Justificativa}

Autores da atualidade sustentam a necessidade da realização de pesquisas que possam contribuir para o desenvolvimento da teoria arquivística. Jardim (1995) salienta que é evidente a necessidade de pesquisas, não só pela "busca de alternativas que evitem a reiteração de projetos malsucedidos", mas também pelas "demandas de soluções a dificuldades específicas do universo arquivístico brasileiro, não contemplados pela literatura internacional" (p.144).

Rousseau e Couture (1998), em busca de uma arquivística mais científica, defendem a arquivística integrada, como sendo a única a assegurar uma política integrada de organização de arquivos, permitindo um rápido acesso às informações, indispensáveis ao funcionamento administrativo das organizações. Trata-se, portanto, de considerar as informações arquivísticas de forma global, através da integração dos procedimentos de classificação, avaliação e descrição, onde a classificação é vista como base para os demais procedimentos.

Consciente disso, o desenvolvimento deste trabalho justifica-se na necessidade de discutir o tratamento da informação arquivística sob o ponto de vista teórico e prático, buscando contribuir para a consolidação da arquivística brasileira.

Em termos práticos, com o conhecimento derivado desta pesquisa pretendese oferecer elementos para a atuação dos profissionais de arquivo, que possam subsidiar o seu fazer no sentido de constituir, manter e gerenciar sistemas de informações arquivísticas. Enquanto docente e na expectativa de contribuir para uma formação que permeia não só o saber fundamental, mas também a compreensão da realidade para que nela se possa agir, espera-se que os resultados desta pesquisa contribuam para a melhoria do ensino universitário. 


\section{FUNDAMENTAÇÃO TEÓRICA}

\subsection{A arquivística}

A arquivística, também conhecida como arquivologia, de acordo com o Dicionário de Terminologia Arquivística (1996), é uma disciplina que

\begin{abstract}
"tem por objeto o conhecimento da natureza dos arquivos e das teorias, métodos e técnicas a serem observados na sua constituição, organização, desenvolvimento e utilização" (p.5).
\end{abstract}

No processo de evolução da arquivística, libertando-se dos conceitos tradicionais de se conceber os arquivos, restritamente ligado ao conceito de documentos, explora-se a valorização do conteúdo informacional dos documentos.

Dentro desta perspectiva, Lopes (1996) define arquivos, no sentido de informações registradas, do seguinte modo:

acervos compostos por informações orgânicas originais, contidas em documentos registrados em suporte convencional (atômicos) ou em suportes que permitam a gravação eletrônica, mensurável pela sua ordem binária (bits); e produzidos ou recebidos por pessoa física ou jurídica, decorrentes do desenvolvimento de suas atividades, sejam elas de caráter administrativo, técnico ou científico, independentemente de suas idades e valores intrínsecos. (p.32)

Valoriza-se a informação sem perder de vista sua organicidade, que permanece na relação de que as informações pertencem a uma pessoa ou a uma organização. A originalidade é enfatizada, considerando a exclusividade, pois são formados por informações específicas dos seus acumuladores. Novas possibilidades são colocadas ao considerar os documentos de arquivo registrados em suportes diversos. A informação arquivística, ou seja, a informação orgânica e registrada, tem ainda como peculiaridade a sua capacidade de ser avaliada em termos de idade e de utilização.

\subsubsection{As informações arquivísticas e as decisões gerenciais}

$\mathrm{Na}$ atualidade, onde se assiste ao aumento, cada vez maior, de informações,

"os arquivos constituem-se órgãos de assessoramento e de pronta informação sobre os documentos produzidos; demonstram que são gestão antes que cultura e história" (KURTZ, 1997, p.94).

Neste sentido, constituem a base para as decisões gerenciais, enquanto elemento de informação e instrumento decisivo no desenvolvimento social, econômico, científico e tecnológico.

Rousseau e Couture (1998), alertam que as organizações nem sempre se percebem de que a informação constitui um recurso fundamental, estando no mesmo nível que os recursos humanos, materiais e financeiros.

As organizações, enquanto sistemas, dependem do funcionamento integrado de sistemas menores ou subsistemas (Arantes, 1994), formando um todo com um objetivo determinado. Considerando que todas as partes utilizam informações, estas tornamse fundamentais na definição dos propósitos e metas organizacionais, na definição de políticas e estratégias a serem seguidas, no desenvolvimento das ações, nas 
decisões a serem tomadas e na avaliação dos resultados.

A arquivística, participando na resolução das questões ligadas à gestão da informação nas organizações, encontra sua vocação. Para corresponder de forma adequada a este desafio, a arquivística precisa

"definir-se em função de uma abordagem integrada e fazer escolhas estratégicas quanto à sua organização interna, às suas alianças e à sua renovação (formação e investigação)" (ROUSSEAU E COUTURE, 1998, p.69).

\subsubsection{Formação profissional}

Ao longo dos anos, um quadro de profundas transformações vem se configurando no campo arquivístico. Neste cenário, Jardim $(1995,1998)$ faz referência às dificuldades com as quais a arquivologia se defronta, ao confronto dos profissionais com as novas questões teóricas e suas repercussões práticas, ao modelo curricular defasado do ponto de vista social, científico e metodológico para o curso de graduação, à ausência de pesquisas que, muitas vezes, leva ao tecnicismo e à neutralidade, acrescentando que isto, no entanto, pode se constituir numa oportunidade de crescimento e desenvolvimento da área.

Segundo Rousseau e Couture (1998), num programa de formação o equilíbrio entre a teoria e a prática só poderá ser alcançado através de estágios num meio de trabalho.

Para Couture, Martineau e Ducharme (1999) a noção de equilíbrio nos cursos de arquivística intervém em dois níveis. Um que se refere à divisão entre ensino teórico e aprendizagem prática, existindo consen- so sobre a igualdade de importância no que se refere a estes aspectos. Outro ligado mais diretamente ao conteúdo das disciplinas e se pauta em três opções: uma visão setorial vinculada aos arquivos administrativos, outra, do mesmo tipo, vinculada aos arquivos históricos e uma terceira, dita integrada, que reúne uma e outra. Para os autores, a escolha de uma opção ou outra está estreitamente vinculada às práticas arquivísticas e às tradições acadêmicas de cada país.

\subsection{A arquivística integrada}

\subsubsection{Da tradição à renovação}

Ao referir-se às correntes e tendências da arquivística, Lopes (1998) parte da premissa da existência de três principais correntes do pensamento arquivístico.

A arquivística tradicional com suas origens principalmente na França, Itália e Espanha, desenvolveu princípios teóricos e práticos para o tratamento dos arquivos definitivos, cuja função primordial é de tornar acessível documentos custodiados. Lopes (1998) numa visão contemporânea, coloca a arquivística tradicional como aquela que

\footnotetext{
"se recusa a questionar a origem, isto é, a criação, a utilização administrativa, técnica e jurídica dos arquivos, dos documentos recolhidos aos arquivos definitivos" (p.61).
}

$O$ records management que surge no período pós-guerra, nos Estados Unidos, quando conceitos e métodos da arquivística tradicional não davam conta da complexidade conseqüente ao aumento explosivo da quantidade de documentos produzidos a serem geridos (LOPES, 1996). Foi traduzida 
pelos canadenses, franceses, espanhóis e outros como gestão de documentos, visando a intervenção da administração arquivística já na fase de produção e tramitação (primeira idade) dos documentos com a finalidade de aplicar métodos de economia e eficácia na gestão documental (SILVA et al., 1999). Os interesses defendidos por esta corrente diferem totalmente dos defendidos pela arquivística tradicional, considerando sua visão administrativa e o estabelecimento de fronteiras entre os conceitos de records e de arquivos. Para Lopes (1998), o records management consiste num "conjunto de regras práticas, por vezes muito eficazes, mas que não possuem fundamentos científicos rigorosos, abrindo a porta à improvisação" (p.61).

A arquivística integrada, desenvolvida no Canadá por Rousseau e Couture (1982, 1998), propõe uma arquivística que se preocupa com o tratamento da informação desde seu nascimento até seu destino final. A arquivística é tratada como a disciplina que agrupa todos os princípios, normas e técnicas que regem as funções de gestão dos arquivos, tais como a criação, a avaliação, a aquisição, a classificação, a descrição, a comunicação e a conservação.

Neste sentido, a arquivística integrada implica atingir três objetivos essenciais:

garantir a unidade e a continuidade das intervenções do arquivista nos documentos de um organismo e permitir assim uma perspectiva do princípio das três idades e das noções de valor primário e secundário; permitir a articulação e a estruturação das atividades arquivísticas numa política de organização de arquivos; integrar o valor primário e o valor secundário numa definição alargada de arquivo (ROUSSEAU E COUTURE, 1998, p.70).

\subsubsection{Teoria das três idades}

Qualquer documento passa por um ou mais períodos caracterizados pelo tipo e freqüência com que são utilizados. Segundo Rousseau e Couture (1998), os três períodos do ciclo de vida dos documentos e as idades que o compõe permite repartir os grandes conjuntos que formam o arquivo de uma pessoa ou organização.

O período de atividade refere-se ao período no qual os documentos formam os arquivos correntes, indispensáveis à manutenção das atividades de uma administração, devendo permanecer o mais próximo possível dos usuários. Os documentos que se encontram nesta fase devem ser conservados para responder aos objetivos da sua criação, considerando que possuem valor primário.

No período de semi-atividade (arquivos intermediários), os documentos são conservados por motivos administrativos, legais ou financeiros, isto é, ainda são detentores de valor primário, mas não mais são utilizados para assegurar as atividades quotidianas da administração.

No período de inatividade, os documentos deixam de ter valor previsível para a organização que os produziu. Assim sendo, podem ser eliminados ou conservados como arquivos definitivos (permanentes), desde que possuam valor de testemunho (valor secundário).

A gestão da informação orgânica, através de um programa em três fases (idades), que permita a pesquisa retrospectiva, parece ser o caminho que conduz a redução de incertezas quando da tomada de decisões pelas administrações. A informação orgânica é utilizada pelas unidades organizacionais não só pelo seu valor primário, quando da tomada e controle de de- 
cisões e ações, mas também pelo seu valor secundário, quando de pesquisas que revelam decisões e ações passadas.

\subsubsection{A classificação, a avaliação e a descrição}

A partir das bases teóricas anteriormente apresentadas, passa-se a discutir as aplicações arquivísticas práticas, as soluções e os problemas relacionados aos procedimentos de classificação, avaliação e descrição na perspectiva de uma abordagem integrada.

Heredia Herrera (1993) refere-se à classificação como uma dimensão intelectual que consiste em separar ou dividir um conjunto de elementos, estabelecendo classes, de tal forma que integrados formam parte de um todo.

Para Rousseau e Couture (1998), através da classificação realizada nos arquivos correntes, a recuperação das informações torna-se mais fácil e rápida, racionalizando seu armazenamento e, conseqüentemente, a sua conservação.

Segundo Lopes (1997), qualquer procedimento relativo à classificação tem repercussões sobre as demais atividades de tratamento das informações. A classificação produz a possibilidade de uma avaliação profunda e o alcance dos objetivos estratégicos de se manter as informações essenciais e descartar as supérfluas, bem como permite dar início a um programa de descrição.

A avaliação consiste num processo, através do qual os documentos são analisados com vistas a estabelecer sua destinação, considerando os valores que Ihe são atribuídos. Como resultado deste processo, tem-se um instrumento básico (tabela de temporalidade) para 0 gerenciamento da documentação e dos arquivos, que permite não só a distinção das informações supérfluas das essenciais, como também o reaproveitamento dos espaços de armazenamento (INOJOSA, 1991).

Considerando que ao se classificar já se está estabelecendo juízo de valor, podese então, classificar, avaliando. Nesta proposta, avalia-se iniciando por classificar. Segundo Lopes (1997), a construção de uma tabela de temporalidade é, ao mesmo tempo, um procedimento classificatório, avaliativo e descritivo, preso à questão do valor das informações.

A descrição, segundo o Dicionário de Terminologia Arquivística (1996, p.23), "consiste no conjunto de procedimentos que, a partir dos elementos formais e de conteúdo, permitem a identificação de documentos e a elaboração de instrumentos de pesquisa".

Schellenberg (1974), Heredia Herrera (1993) e Bellotto (1991), entre outros, ao tratarem de programas descritivos referemse aos arquivos definitivos. No entanto, Lopes (1996) acredita que

\footnotetext{
"dentro da perspectiva da arquivística integrada, a descrição começa no processo de classificação, continua na avaliação e se aprofunda nos instrumentos de busca mais específico" (p.101).
}

Ao considerar as operações de natureza intelectual, o autor coloca que, sem exceções, são de natureza descritiva e, conclui que é difícil separar a descrição dos outros dois procedimentos fundamentais da prática arquivística.

Sob esta perspectiva, um programa descritivo, deveria então, iniciar-se de fato 
com a classificação, onde se alcançaria o primeiro nível do processo (planos, esquemas ou quadros de classificação). O segundo, se daria com a avaliação (tabelas de temporalidade) e o terceiro e mais detalhado ocorreria nos arquivos permanentes (guias, inventários)

\subsubsection{Métodos de classificação}

$\mathrm{Na}$ concepção de uma arquivística integrada, pensa-se na classificação na primeira fase do ciclo vital dos documentos, a qual seria mantida no essencial no decorrer do ciclo, até os arquivos definitivos. Uma classificação que possibilite a localização das informações e documentos, que torne realizável a avaliação e que permita o início de um programa de descrição.

Schellenberg (1974) apresenta métodos de classificação, através dos quais é possível estabelecer o arranjo dos documentos, segundo um plano destinado para facilitar seu uso. Os planos, esquemas ou quadros de classificação consistem da estruturação hierárquica e lógica, organizada intelectualmente, que permite situar as informações e os documentos em suas relações uns com os outros.

Através do método de classificação funcional, o agrupamento dos documentos deve se dar por atos, por função. Assim, na elaboração divide-se os documentos em classes e subclasses, onde as maiores classes ou classes principais são criadas tomando-se por base as maiores funções e as classes secundárias considerando as atividades. Pelo método de classificação organizacional, a estrutura orgânica forma a base para os grandes agrupamentos de documentos. Assim, as classes primárias, em geral, representam os principais elementos organizacionais. No método de classificação por assunto, devem ser retirados da análise dos documentos, os assuntos que farão parte do plano.

A escolha do método de classificação a ser adotado é, sem dúvida, um dos pontos mais importantes, se considerarmos a perspectiva da arquivística integrada, pois dele dependerá o desencadeamento de todo o processo.

\section{METODOLOGIA}

A pesquisa realizada consiste em um estudo qualitativo, portanto uma pesquisa descritiva (GODOY, 1995). O estudo foi conduzido através da pesquisa documental, cujas fontes constituem-se dos trabalhos de final de curso dos graduandos em Arquivologia da UFSM, no período 1997 a 1999.

Considerando a abrangência do presente estudo, não foi realizada a definição constitutiva e operacional de variáveis, sendo destacadas para a análise as seguintes categorias: aplicação da arquivística integrada, interligação dos procedimentos da classificação, avaliação e descrição, aplicação do procedimento de classificação, problemas de ordem téorico-prático apontados.

Para análise foram considerados os trabalhos resultantes da disciplina de Projeto de Arquivo e de Estágio Supervisionado, totalizando 50 trabalhos, realizados pelos alunos, no período delimitado para realização da pesquisa (1997 a 1999). Destes, foram analisados 47 trabalhos, três não se encontravam no acervo quando foram realizadas as análises. Foram utilizados códigos representados por (TR 01, TO 02, TPR 03), correspondendo TR 01, por exemplo, ao relatório 01 ; TP 02 , ao projeto 02 ; e TPR, ao relatório e projeto 03 , realizados na mesma instituição. 
Para encontrar respostas à questão que norteou esta pesquisa, foi então, empregada a técnica de análise de conteúdo, orientada por Gomes (1996); Godoy (1995) e por Bogdan e Biklen (1994). Inicialmente realizou-se uma pré-análise, com o objetivo de organizar um esquema de trabalho que orientasse para a análise, com procedimentos bem definidos, embora flexíveis.

Posteriormente, os trabalhos dos graduandos foram percorridos com o objetivo de destacar frases e parágrafos representativos das idéias, reflexões, estratégias e perspectivas dos alunos em relação aos tópicos em estudo. Uma vez coletados os dados, procedeu-se a releitura dos mesmos em busca de regularidades e padrões, partes ou elementos comuns e particulares.

Após, os dados foram agrupados, organizados e apresentados como resultados. Posteriormente, procedeu-se a análise e interpretação daquilo que os dados revelaram. Esta etapa foi orientada pela questão de pesquisa e discutida com os autores que discorrem sobre o tema.

Assim, "num movimento contínuo da teoria para os dados e vice-versa" (GÓDOY, 1995, p.24), as categorias de análise tornaram-se cada vez mais claras e apropriadas aos propósitos das pesquisa, o que permitiu elaborar as considerações finais, considerando a análise dos resultados.

\section{RESULTADOS E ANÁLISE}

\subsection{As políticas de gestão de arquivos}

$\mathrm{Na}$ maioria dos trabalhos analisados percebe-se bem clara a preocupação dos graduandos em Arquivologia pela UFSM com a gestão sistemática das informações para o processo decisório das organizações, evidenciando-se a relação desta com a implantação de sistemas de arquivos centrados em programas de gestão das informações ao longo do ciclo vital (três idades).

Através das argumentações, observase o interesse em implantar sistemas de arquivos considerando os pressupostos teóricos da arquivística integrada. No entanto, observa-se que em alguns trabalhos, mesmo que poucos, o interesse voltado para o tratamento dos documentos de terceira idade, desconsidera a origem dos mesmos.

Assim, apesar de haver indícios de aplicação da arquivística tradicional, podese inferir que são raras essas aplicações. Para Lopes (1998), a arquivística tradicional

"se recusa a questionar a origem, isto é, a criação, a utilização administrativa, técnica e jurídica dos arquivos, dos documentos recolhidos aos arquivos definitivos" (p.61).

\subsection{A interligação entre os procedimentos de classificação, avaliação e descrição.}

Considerando os fundamentos teóricos, na perspectiva da arquivística integra$\mathrm{da}$, através dos resultados observa-se que são reconhecidas as peculiaridades de cada fase do ciclo vital.

Na maioria dos trabalhos analisados, a avaliação é discutida e realizada, no âmbito dos arquivos correntes, tendo por base a classificação. O processo de avaliação é entendido como "um trabalho que consiste na identificação de valores para os documentos e na análise do ciclo de vida dos mesmos." (TR 15, 1999, p.30). 
Nesse sentido, percebe-se através dos resultados, a aplicação da teoria das três idades, vinculada aos valores dos documentos, o que vem contrariar as colocações de Lopes (1996), quando diz que é raro encontrar exemplos vivos da aplicação da teoria das três idades, apesar de que, na América Latina muito se conhece sobre ela.

Nestes trabalhos, reconhece-se que a classificação e avaliação andam juntas, enquanto procedimentos complementares e inseparáveis, objetivando manter o controle sobre os documentos, impedindo seu crescimento demasiado e ordenando-os para que as informações possam ser acessadas.

Aqui, possivelmente, encontra-se o ponto crítico no entendimento dos graduandos a respeito da arquivística integrada, na medida em que não estabelecem relação da descrição com os demais procedimentos, ou, simplesmente não se referem a este procedimento. Na maioria deles, a descrição é vista como um procedimento que deve desenvolver-se nos arquivos de terceira idade,

\footnotetext{
"elaborados a partir de um estudo mais aprofundado da documentação de caráter permanente, bem como das necessidades do pesquisador, com relação à documentação." (TP 43, 1997, p.39).
}

A descrição é uma função arquivística central, ligada diretamente à classificação (COUTURE, 1998). Assim, considerando as operações de classificação de natureza intelectual, estas são, "sem exceção de natureza descritiva" (LOPES, 1997, p.69), tornando-se então, difícil separar a descrição da classificação e da avaliação.

\subsection{A aplicação do procedimento de}

\section{classificação}

Na maioria dos trabalhos é evidente a preocupação com o procedimento de classificação, onde se salienta que a realização deste deve ocorrer nos arquivos correntes, ou seja, na primeira idade do ciclo, devendo manter-se nas demais.

Rousseau e Couture (1998) argumentam que a classificação realizada nos arquivos correntes, torna a recuperação das informações mais fácil, rápida, racionalizando seu armazenamento, bem como sua conservação.

\subsubsection{Os métodos de classificação}

Muitos argumentos são apresentados para justificar a aplicação de métodos de classificação, salientando-se a aplicação do método de classificação funcional, na maioria dos trabalhos analisados, apesar de Gonçalves (1998) considerar a classificação funcional, menos freqüente, mas que atende melhor às exigências da classificação arquivística.

Os resultados demonstram a preocupação com procedimento de classificação, na medida em que os graduandos pensam e/ou aplicam este procedimento desde o momento em que os documentos são criados até o momento de seu destino final. Nesse sentido, tem-se a classificação repercutindo sobre outras atividades de tratamento das informações. Assim, reconhecem as teorias de Rousseau e Couture (1982, 1998), com os quais deu-se início a idéia de tratamento global dos arquivos (LOPES, 1998).

Este quadro remete ao comentário de que existe a preocupação dos graduandos em classificar os documentos através de metodologias apropriadas, na medida que reconhecem e usam os fundamentos teóri- 
cos sobre 0 assunto, buscando classificar os documentos de forma a agilizar a recuperação das informações contidas nos documentos. O que para Alberch i Fugueras (1997), defensor de um sistema de classificação uniforme, só é possível através de uma estrutura hierárquica e lógica que reflete as funções e atividades de um organismo.

\subsubsection{A elaboração de planos de classificação}

$\mathrm{Na}$ maioria dos trabalhos analisados os procedimentos metodológicos adotados, quando da elaboração de planos, esquemas ou quadros de classificação, apresentam-se pouco detalhados e sem muito destaque, onde não se observa a descrição dos mesmos em itens próprios. Apesar disso, evidencia-se a preocupação em conhecer a história das organizações, sua estrutura e funcionamento, bem como as características dos acervos, para através da coleta de dados, proceder a análise, com vistas à adoção de métodos de classificação.

Para Lopes (1996), a classificação deve se dar de "modo heurístico" (p.98). Assim, o conjunto de classes/séries informacionais e documentais deve refletir o que se estudou sobre as estruturas, as funções, as atividades e as características dos acervos. Dessa forma, pode-se estruturar logicamente uma hierarquia de classes/séries não estranhas à organização que permitirão o acesso às informações.

De acordo com os resultados encontrados, a importância do princípio da proveniência parece claramente reconhecida em alguns trabalhos, onde observa-se a preocupação em apresentar planos de classificação estabelecendo as relações da instituição e sua estrutura enquanto constituidores de fundos, grupos, séries, etc., como por exemplo, o trabalho TR 09 (1999). No entanto, cabe destacar que as reflexões e argumentos nesse sentido encontrarem-se praticamente ausentes.

Lopes (1997) argumenta que a classificação deve basear-se na definição de fundos, subfundos, séries, subséries, etc., quando coloca que "um dos pontos cruciais da teoria arquivística é o princípio da proveniência, isto é, o respeito à origem do acervo." (p.63).

\subsubsection{Os resultados da aplicação de métodos de classificação}

Na maioria dos trabalhos analisados, não se destaca os resultados obtidos com a aplicação de métodos de classificação para fins de organização das informações arquivísticas. Nos trabalhos, que apresentam resultados, evidenciam-se que, da classificação aplicada, resulta agilidade na busca das informações, facilitando o acesso, como forma de subsidiar as decisões administrativas.

Isto vem reafirmar algumas das colocações feitas por Rousseau e Couture (1998), quando referem-se a classificação realizada, através da qual a recuperação das informações torna-se mais fácil e rápida, além de outras vantagens.

\subsection{A teoria e a prática}

Na maioria dos trabalhos analisados, evidencia-se o reconhecimento da importância da realização de práticas através dos estágios, como forma de aplicar a teoria arquivística. Assim, encontra-se bem consistente a argumentação de que os estágios e trabalhos práticos realmente permitem a integração entre a teoria e a prática realizada, visto que, dessa forma é possível aplicar os conhecimentos teóricos e vivenciar uma realidade.

No mesmo sentido, Rousseau e Couture (1998, p.274) argumentam que "o 
equilíbrio entre a teoria e a prática não poderá ser alcançado sem que um lugar de eleição seja atribuído ao estágio num meio de trabalho".

As limitações e dificuldades reconhecidas parecem servir de estímulo às "discussões construtivas" (TR 03, 1999, p.36) e à busca constante não só de conhecimento e aperfeiçoamento, como também de alternativas de solução frente aos problemas enfrentados, que muitas vezes, vão "além de organizar arquivos” (TR 17, 1999, p.22).

Dessa forma, além da valorização da prática para a preparação profissional, percebe-se a valorização atribuída também à dimensão teórica como qualificadora da prática realizada. Neste contexto, pode-se fazer referência a Jardim (1995) que ao colocar as dificuldades com as quais a arquivologia se defronta, acrescenta que as mesmas podem se constituir em oportunidade de crescimento e desenvolvimento da área.

Além disso, através dos resultados apresentados, pode-se deduzir que os conteúdos das disciplinas estão voltados para uma visão integrada, preocupada não só com os arquivos administrativos, mas também com os históricos. Para Lopes (1998), a partir da arquivística integrada, talvez, possa chegar-se às soluções teóricas e práticas que estejam de acordo com a situação específica de cada país e a métodos de trabalhos adaptáveis às realidades diferentes.

\section{CONSIDERAÇÕES FINAIS}

Retomando os objetivos que norteia a realização deste trabalho, pode-se inferir que do ponto de vista cronológico, observa-se uma evolução das possibilidades de aplicação de uma política integrada de ar- quivos, através da implantação de programas de gestão das informações ao longo do ciclo vital.

Na prática, os arquivos são divididos por idade, havendo, portanto exemplos vivos da aplicação da teoria das três idades no Brasil, considerando o entendimento dos arquivos na sua totalidade, onde se reconhece as peculiaridades nas suas várias idades (arquivo corrente, intermediário e permanente).

A classificação e avaliação são vistas como inseparáveis e complementares, existindo uma certa homogeneidade nas práticas de classificar e avaliar documentos, refletida nos argumentos, nos métodos e nos instrumentos apresentados (planos de classificação e tabelas de temporalidade).

Por outro lado, o procedimento de descrição não é entendido como resultante do conjunto de procedimentos que se desenvolve ao longo do ciclo vital e que torna-se mais detalhada nos arquivos permanentes, estando relegado a se desenvolver no âmbito dos arquivos permanentes, separado dos procedimentos de classificação e avaliação. Observa-se aí, a forte herança deixada pelos autores que referem-se a programas descritivos desenvolvidos apenas no âmbito dos arquivos permanentes.

A classificação é pensada a partir da criação dos documentos até o momento de seu destino final, repercutindo assim, sobre os demais procedimentos de tratamento das informações arquivísticas. Assim, a classificação constitui o eixo principal do fazer arquivístico, na medida em que possibilita a localização das informações e dos documentos, bem como torna realizável o processo de avaliação.

A classificação proposta e ou aplicada é resultante de estudos realizados no âmbi- 
to das organizações, do reconhecimento dos fundamentos teóricos sobre o tema e da aplicação de métodos que permitem hierarquizar as informações, do geral para o particular, fornecendo bases para o arquivamento das informações.

Têm-se, então, as bases da classificação propostas por Schellenberg (1974) ainda aplicadas e atendendo às exigências da classificação arquivística atual, bem como o entendimento e aplicação dos pressupostos teóricos da arquivística integrada, sendo consideradas as obras de Rousseau e Couture (1998) e Lopes (1996, 1997, 1998).

Apesar disso, existem limitações teóricas refletidas na ausência de reflexões e argumentos sobre a aplicação do princípio da proveniência, sobre os procedimentos metodológicos aplicados para a elaboração dos planos de classificação e sobre os resultados obtidos com a aplicação de planos de classificação.

Os estágios realizados nas organizações permitem integrar a teoria arquivística à prática realizada, possibilitando a aplicação dos conhecimentos teóricos, preparando, assim, os graduandos em Arquivologia para atuarem no mercado de trabalho. Dessa forma, os estágios cumprem sua finalidade, promovendo a integração entre o curso - universidade e as instituições - e a sociedade.

Os graduandos desenvolvem seus trabalhos intelectualmente, considerando as questões teórico-conceituais como relevantes na sua formação, considerando a valorização atribuída não só à dimensão prática, mas também à dimensão teórica como qualificadora da prática realizada.

Observa-se que há um certo equilíbrio entre o ensino teórico e a prática realizada, constatado nos trabalhos de final de curso dos graduandos, onde se reflete a formação dos mesmos. Os conteúdos disciplinares estão voltados para uma visão integrada, preocupada com o tratamento global dos arquivos.

Isto posto, apesar de encontrados indícios da aplicação da arquivística tradicional, conclui-se que os graduandos em Arquivologia estão, cada vez mais, reconhecendo e aceitando a arquivística integrada, aplicando-a considerando os desdobramentos do processo a partir da classificação.

Acredita-se que, através da arquivística integrada, de uma arquivística mais científica, pode-se responder adequadamente aos problemas do momento atual.

As informações, enquanto elementos fundamentais de apoio às decisões gerenciais, precisam ser acessadas para que possam constituir fonte de conhecimento, porém isto só é possível se fizerem parte de um conjunto sistemático, estruturado e organizado. Os profissionais devem procurar iniciativas que visem atender às tendências atuais, buscando gerir as informações organizacionais de forma integrada, viabilizando o acesso e a utilização dos arquivos.

O mercado exige uma formação que permita capacitar os profissionais a atuarem frente aos problemas contemporâneos. Para tanto, mudanças são impostas, face às dificuldades e limitações ora consideradas.

Esforços nesse sentido devem ser dispensados pelos docentes do curso de Arquivologia da UFSM, para refletir sobre a criação, desenvolvimento e consolidação de programas de formação, cada vez mais, adequados, que garantam um ensino de qua- 
lidade, assim como o aumento de pesquisas.

Através da arquivística, enquanto campo do conhecimento vinculado à gestão da informação, pode-se, numa visão sistêmica, provocar mudanças que envolvam e integrem todas as dimensões organizacionais. Assim, entende-se que outros estudos precisam ser desenvolvidos, pois há muito a ser feito através da pesquisa científica, para contribuir com a ascensão e a consolidação da arquivística.

\section{REFERÊNCIAS}

ALBERCH i FUGUERAS, Ramon. El tratamiento de los documentos: acceso, clasificación, evaluación. La función administrativa y la función cultural. Barcelona, Espanha : Archivo Municipal de Barcelona, 1997.

ARANTES, Nelio. Sistema de gestão empresarial. São Paulo : Atlas, 1994.

BELLOTTO, Heloísa L. Arquivos permanentes: tratamento documental. São Paulo : T. A. Queiroz, 1991.

BOGDAN, Robert C.; BIKLEN, Sari K. Investigação qualitativa em educação: uma introdução à teoria e aos métodos. Porto, Portugal : Porto Editora. 1994.

COUTURE, Carol. Archivistique intégrée et politique de gestion des archives: propositions innovatrices? Arquivo\&História, Rio de Janeiro, n.4, p.5-36, out., 1998.

COUTURE, Carol; MARTINEAU, Jocelyne; DUCHARME, Daniel. A formação e a pesquisa em arquivística no mundo contemporâneo. Brasília : Finatec, 1999. DICIONÁRIO de terminologia arquivística. Coord. Ana Maria de Almeida Camargo. São
Paulo : AAB/SP; Secretaria do Estado da Cultura, 1996.

GODOY, Arilda Schmidt. Introdução à pesquisa qualitativa e suas possibilidades. Revista de Administração de Empresas, São Paulo, v.35, n.2, p. 57-63, mar./abr., 1995.

. Pesquisa qualitativa: tipos fundamentais. Revista de Administração de Empresas, São Paulo, v.35, n.3, p. 20-29, mai./ jun., 1995.

GOMES, Romeu. A análise de dados em pesquisa qualitativa. In: Pesquisa social: teoria, método e criatividade. Petrópolis : Vozes, 1994. p.67-80.

GONÇALVES, Janice. Como classificar e ordenar documentos de arquivo. São Paulo : Arquivo do Estado, 1998.

HEREDIA HERRERA, Antonia. Archivística general: teoría y práctica. Sevilla, Espanha : Diputación Provincial de Sevilla, 1993.

INOJOSA, Rose Marie. Tabelas de Temporalidade. In: A sistematização de arquivos públicos. Org. Ataliba T. de Castilho. Campinas : UNICAMP, 1991. p.87100.

JARDIM, José Maria. A universidade e o ensino de arquivologia no país. In: Algumas reflexões sobre o ensino e práticas na área da informação. Niterói : EDUFF, 1998. p. 63-82. (Estudos\&Pesquisas; 2).

Novas perspectivas da arquivologia nos anos 90. In: A informação: questões e problemas. Niterói : EDUFF, 1995. p. 2738. (Estudos\&Pesquisas; 1).

Sistemas e políticas públicas de arquivos no Brasil. Niterói : EDUFF, 1995. 
KURTZ, Clara Marli S. Arquivística contemporânea. In: Textos de arquivologia. Santa Maria : UFSM; AAB/RS, 1997. p. 91-99.

LOPES, Luís Carlos. Os arquivos, a gestão da informação e a reforma do estado. Arquivo\&História, Rio de Janeiro, n.4, p.37-49, out., 1998.

A imagem e a sombra da arquivística. Rio de Janeiro : APERJ, 1998.

A gestão da informação: as organizações, os arquivos e a informática aplicada. Rio de Janeiro : APERJ, 1997.

A informação e os arquivos: teorias e práticas. Niteói : EDUFF; São Carlos : EDUFSCar, 1996.

ROUSSEAU, Jean-Yves; COUTURE, Carol. Les archives au $\mathrm{XX}^{\mathrm{e}}$ siècle. Montreal, Canadá : Université de Montréal, 1982.

Os fundamentos da disciplina arquivística. Lisboa, Portugal : Nova Enciclopédia, 1998.

SCHELLENBERG, Theodore Roosevelt. Arquivos modernos: princípios e técnicas. Rio de Janeiro : FGV, 1974.

SILVA, Armando Malheiro da et al. Arquivística: teoria e prática de uma ciência da informação. Porto, Portugal : Ed. Afrontamento, 1998.

\section{Olga Maria Correa Garcia}

Graduada em Arquivologia pela Universidade Federal de Santa Maria/RS

Especialista em Pesquisa pela Faculdade de Filosofia Ciências e Letras Imaculada Conceição/Santa Maria/RS

Mestre em Administração pela Universidade Federal de Santa Catarina Professora Assistente/ Departamento de Documentação

Centro de Ciências Sociais e Humanas/ Universidade Federal de Santa Maria garcia@ccsh.ufsm.br

\section{Vitor Francisco Schuch Júnior}

Graduado em Administração pela Universidade Federal de Santa Maria/RS

Mestre em Administração pela Universidade Federal do Rio Grande do Sul/POA/RS Doutor em Educação pela Universidade Federal de Santa Maria/convênio UNICAMP Professor titular aposentado na Universidade Federal de Santa Maria/RS Coordenador do Curso de Administração da Faculdade Ritter dos Reis/POA/RS

\section{Title}

The application of the integrated approach to archives, considering the process starting from classification

\section{Abstract}

This article investigates the aplication of the integrated approach to archives, considering the process starting from classification, using the students' essays written to conclude the Undergraduate Course in Archive Science at the Federal University of Santa Maria, from 1997 to 1999. It was employed the analysis of content, developed through a documental pre-analysis, material exploration and handling, and results interpretation. It was possible to conclude that, despite of finding some traces of traditional approach to archives application, the under- 
graduate students increasingly recognize and accept the integrated approach, applying it considering the process starting from classification. Because of dificulties and limitations presented by undergraduate students, it was noticed that changes are necessary, in the sense of developing and consolidating syllabus that should garantee an education of quality and an increase in research.

\section{Keywords}

Integrated Approach to Archives; Documentary Classification: Archives Management Policy.

\section{Titulo}

La aplicación de la Archivística integrada, considerando los desdoblamientos del proceso a partir de la Clasificación

\section{Resumen}

Investiga la aplicación de la archivística integrada, considerando los desdoblamientos del proceso a partir de la clasificación, en los trabajos del final de curso de los graduandos en Archivología por la Universidad Federal de Santa María, en el período de 1997 a 1999. Utiliza la técnica de análisis del contenido, desarrollada a través de una pré-análisis de las fuentes, de la exploración del material y del tratamiento e interpretación de los resultados. Así, concluye que, a pesar de encontrar indicios de aplicación de la archivística tradicional, los graduandos, cada vez mas, reconocen y aceptan la archivística integrada, aplicando y considerando los desdoblamientos del proceso a partir de la clasificación. Face a las dificultades y limitaciones presentadas por los graduandos, se reconoce que son necesarios cambios, en el sentido de desarrolar y consolidar los programas de formación.

\section{Palabras-clave}

Archivística; Archivística Integrada; Clasificación Documentária; Política de Gestión de Archivos

\section{Artigo recebido em: 08/10/2001}

